\title{
Ammonia as a Pheromone in Anuran Tadpoles
}

\author{
Y. B. MANTEIFEL ${ }^{1}$, E. I. KISELEVA ${ }^{1}$ \\ ${ }^{1}$ Severtsov Institute of Ecology and Evolution, Russian Academy of Sciences, Moscow, Russia
}

Received January 25, 2011

Accepted March 30, 2011

On-line July 19, 2011

\section{Summary}

In laboratory experiments, conspecific excretions and ammonia solutions evoked avoidance reactions in tadpoles of three anuran species, Bufo bufo, Rana temporaria, and Rana arvalis. A differential sensitivity of ammonia chemoreception was determined for two anuran species. For Bufo bufo tadpoles, these characteristics at ammonia background concentration of $0.2 \mathrm{mg} / \mathrm{l}$ lied in the range $150 \%<\mathrm{dI} / \mathrm{I}<500 \%$, and for background of $0.4 \mathrm{mg} / \mathrm{l}$ the value lied in the range $400 \%<\mathrm{dI} / \mathrm{I}<500 \%$. For Rana temporaria tadpoles, differential threshold against ammonia background concentration of $0.15 \mathrm{mg} / \mathrm{l}$ was close to $200 \%$ and against background ammonia concentration of $1.1 \mathrm{mg} / \mathrm{l}$ was close to $100 \%$. These results suggest that such sensitivity of both anurans is sufficient for using ammonia in intra- and interspecies communication.

\section{Key words}

Disturbance pheromone - Ammonia • Sensitivity • Amphibians • Larvae

\section{Corresponding author}

Y. B. Manteifel, Severtsov Institute of Ecology and Evolution, Russian Academy of Sciences, Leninsky Pr. 33, 119071 Moscow, Russia. E-mail: mantei@yandex.ru

\section{Introduction}

Unlike studies on volatile odorants perception, the investigations of chemoreception in aquatic media can more accurately evaluate the concentrations of stimuli, because the movement of signaling molecules in water is largely determined by transport of solutions. The significance of concentration gradients of pheromones and nutrients for the localization of the stimuli sources by decapods and some fish has repeatedly proved. It seems symptomatic that the Journal of Chemical Ecology (2008, Vol 34, No 4) published a special collection of invited papers dedicated to distribution of chemical stimuli in media. However, to date this promising theme is not sufficiently developed.

Studies on absolute and differential sensitivities of vertebrates to natural chemical stimuli are difficult because such stimuli, as a rule, are mixtures of several substances. The decreasing effectiveness of stimulating mixture after dilution could be a consequence of both a reduced concentration and a decreased content of effective mixture components. Therefore, the research on responses of aquatic animals to simple natural stimuli, like ammonia, seems very perspective. This substance is the predominant final product of nitrogenous metabolism in a number of aquatic animals, including anuran larvae (Duellman and Treub 1986), and the tadpoles are convenient objects for such research. It has been shown in many studies that the distribution of tadpoles in natural waters and their motor activity are influenced by chemical stimuli. For all studied tadpoles, behavioral responses to predator excretions were revealed, and in some species alarm pheromones are released into the water when the epidermis of other conspecifics is damaged (Pfeiffer 1974). Responses to such chemical stimuli reduce the probability of death in the reacting individuals.

In experiments with tadpoles of Rana aurora, it was observed that avoidance responses of these animals could be evoked by conspecific excretions and ammonia containing in them (Kiesecker et al. 1999). The authors suggested that the excretions contain a disturbance pheromone, and ammonia excreting with urea could be this substance. Ammonia is always present in natural waters. Consequently, the possibility of perception of 
increasing concentration of ammonia by tadpoles depends on the relationship between the relative increase in the stimulus concentration and differential sensitivity to it. The study of the characteristics can elucidate, which range of ammonia background levels and which increasing ammonia concentration in the cloud of tadpole excretions limit possible using this substance as disturbance pheromone in tadpoles.

The first purpose of this study was to investigate tadpole behavioral reactions of three anuran species Bufo bufo, Rana temporaria and Rana arvalis to excretions of conspecific tadpoles and to aqueous ammonia solutions. So, we determined the extent of tadpole's reaction to disturbance pheromone and to ammonia elevated concentrations as a presumptive disturbance pheromone or its effective component. The second purpose was to clarify the possibility of ammonia being a pheromone in the nature. For this purpose, we studied the differential thresholds of behavioral avoidance caused by ammonia presentation on different background concentrations of the substance in water. This study was made on two tadpole species Bufo bufo and Rana temporaria that were selected because their antipredator adaptations differ significantly.

\section{Methods}

The laboratory studies have been made on the toad Bufo bufo and frogs Rana temporaria and Rana arvalis tadpoles at Hydrobiologic Station "Glubokoe Lake" (Moscow region, Russia). Tadpoles at developmental stages 36-39 (Gosner 1960) were collected from the lake. The animals were used in one trial only and then returned to the lake. The experiments were made in the transparent plastic test aquaria, with dimension of $58 \times 9 \times 8 \mathrm{~cm}$. Two perforated plates partitioned end parts $5 \mathrm{~cm}$ in length from the middle section, called the test chamber. The bottom of the test chamber was divided into three zones of equal length (one central and two end zones) by visible lines (Fig. 1). Using such aquaria, we compared the times that individual animal spent in two end zones after the addition a pair of compared stimuli into both end parts (Manteifel 1995). Initially each aquarium contained 0.71 of lake water $(1.3 \mathrm{~cm}$ depth). Experiments were made in a darkened room and the test aquarium was illuminated with electric $75 \mathrm{~W}$ lamp located $1.5 \mathrm{~m}$ above it. Both end zones were lighted uniformly.

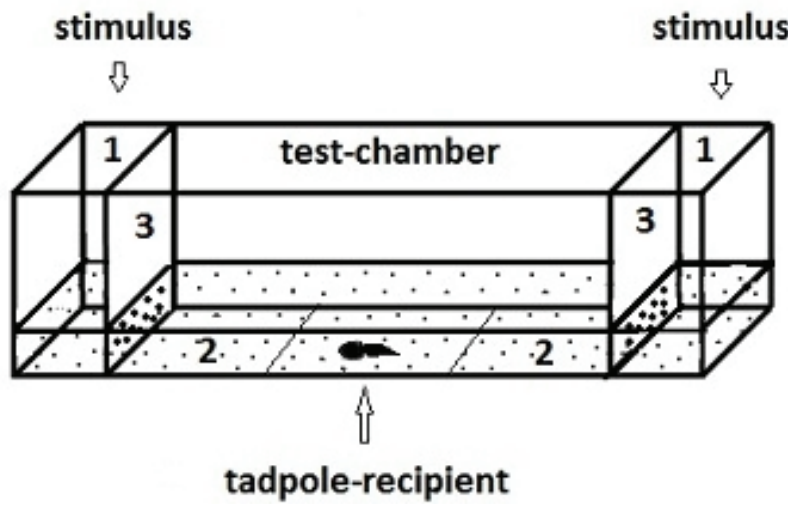

Fig. 1. Schematic picture of the test aquarium. 1, the end parts of the aquiarium; 2 , the end zones; 3 , perforated partitions.

Preliminary experiments revealed that concentration of a stimulus in the end zone was five times lower than initial value in the end part. Therefore, stimuli concentrations given in the article reflect this dilution. The stimulus concentration in the end zone remained almost unchanged for $60 \mathrm{~min}$ as a result of inflow from the end part through a perforated plate. Movements of tadpole do not create remarkable turbulence in the water (Wassersug and von Seckendorf 1985) and a tadpole does not significantly alter the distribution of a stimulus.

At the beginning of experiments, individual tadpole-recepient was placed in the center of the test chamber. After $15 \mathrm{~min}$ of acclimation, the control stimulation was done by adding $100 \mathrm{ml}$ of the lake water in both end parts simultaneously. After one minute, location of the tadpole was recorded every $10 \mathrm{~s}$ during 10 -min period. Then $100 \mathrm{ml}$ of the test stimulus was added into one end zone and $100 \mathrm{ml}$ of lake water into another end zone. After one minute, the registration of tadpole location was repeated. Side of test stimulus was changed every trial. After every trial, test aquarium was carefully washed with lake water without detergents. Temperature of all stimuli was equal to that of water in the test aquarium $\left(18 \pm 1^{\circ} \mathrm{C}\right)$.

In total, 1107 active tadpoles were used in the study, 15-40 individuals in each experiment. The number of animal visits in the stimulus-containing end zone during control or stimulation period was expressed as the percentage of the total recording number in both end zones. This value was called "the choice index". A resulting criterion, "the avoidance index", was a difference between the choice index during control period and that for stimulation period. The positive value of avoidance index means that the tadpole was within a "cloud" of the test stimulus for a shorter time, then in a 
Table 1. Reactions of larvae of three anuran species to chemical stimuli: avoidance indices (percentages and standard errors) and significance of the reaction compared to control.

\begin{tabular}{lcccccc}
\hline \multirow{2}{*}{$\begin{array}{l}\text { Amphibian } \\
\text { species }\end{array}$} & \multicolumn{2}{c}{ Excretions of conspecifics } & $\mathbf{N H}_{\mathbf{3}}+\mathbf{0 . 2} \mathbf{~ m g} / \mathbf{l}$ & \multicolumn{2}{c}{$\mathbf{N H}_{\mathbf{3}}+\mathbf{1 . 0} \mathbf{~ m g} / \mathbf{l}$} \\
\cline { 2 - 7 } & $\begin{array}{c}\text { Avoidance indices } \\
\mathbf{\%}\end{array}$ & $\mathbf{p}$ & $\begin{array}{c}\text { Avoidance indices } \\
\mathbf{\%}\end{array}$ & $\mathbf{p}$ & $\begin{array}{c}\text { Avoidance indices } \\
\mathbf{\%}\end{array}$ & $\mathbf{p}$ \\
& & & & & & \\
\hline Bufo bufo & $16.7 \pm 3.16$ & $<0.000$ & $16.2 \pm 4.12$ & $<0.001$ & $29.5 \pm 3.54$ & $<0.000$ \\
Rana temporaria & $16.0 \pm 5.94$ & $<0.000$ & $3.3 \pm 4.45$ & $>0.99$ & $23.5 \pm 5.00$ & $<0.000$ \\
Rana arvalis & $8.9 \pm 3.28$ & $<0.01$ & $14.9 \pm 4.33$ & $<0.001$ & $14.6 \pm 3.83$ & $<0.001$ \\
\hline
\end{tabular}

control end chamber. The registration time continued $10 \mathrm{~min}$ because the avoidance indices for reaction to effective stimuli were stable during this period. In all experiments, the tadpoles of all three species did not prefer any side of the aquarium during the control period. Neither the individual choice indices nor the average choice index differed significantly from the random choice value $50 \%$. Thus, the influence of any unknown factors on tadpole behavior was detected in the used experimental conditions.

The ammonia concentration was determined by a photometrical method after reaction with Nessler reagent in ammoniameter with an operating range $0.04-3 \mathrm{mg} \mathrm{NH} / 1$ of water. The concentration of impurities in commercial solution of ammonia was about $10^{6}$ times lower than the main substance. The lake water served as a solvent. The concentration of ammonia in the stimulus solutions designated as excess above the background.

To obtain conspecific excretions, 7-11 tadpoledonors were placed for $30 \mathrm{~min}$ in a cylindrical glass vessel $(10 \mathrm{~cm}$ in diameter) containing $650 \mathrm{ml}$ of lake water. The real concentrations of excretions were unknown. Therefore, the preparative concentrations (the value of donor body weight multiplied by accumulation time and divided by the water volume) served as characteristics of such stimuli. These concentrations were in the range $0.3-0.6 \mathrm{~g} \cdot \mathrm{h} / \mathrm{l}$, which was close to the value used in the work with $R$. aurora (Kiesecker et al. 1999). During the entire period of excretions accumulation, the donors were moving along the vessel walls. In experiments with $B$. bufo two donor groups were used: the second group was mechanically activated for $1 \mathrm{~min}$ after 29 min of accumulation. All stimuli (including the lake water for filling the test aquaria) were filtered through the plastic net with a mesh size of $0.25 \mathrm{~mm}$.

Water containing $3 \mathrm{mg} / \mathrm{l}$ ammonia is toxic to some animals. According to our observations, the concentration of ammonia in water of mesotrophic Glubokoe Lake is $0.06-0.1 \mathrm{mg} / 1$. Using this natural water is an important peculiarity of our technique. For reduction of ammonia level up to $<0.04 \mathrm{mg} / \mathrm{l}$ we aerated the water during about $10 \mathrm{~h}$.

For analysis, the choice indices (determined in the control and experimental periods) were compared using Wilcoxon test. The experimental results are presented in the tables as arithmetic means and their standard errors. Differences in responses to different stimuli are defined by bilateral Mann-Whitney test with Bonferroni correction.

\section{Results}

Avoidance of conspecific excretions and ammonia by tadpoles of anurans B. bufo, $R$. temporaria and $R$. arvalis

The tadpoles demonstrated behavior responses in double-choice experiments when two stimuli were presented in the water with background ammonia level of $0.05-0.1 \mathrm{mg} / \mathrm{l}$. Test stimuli were conspecific excretions in a preparative concentration of about $0.1 \mathrm{~g} \cdot \mathrm{h} / 1$ or ammonia solutions with concentrations of +0.2 and $+1.0 \mathrm{mg} / \mathrm{l}$ (12 and $60 \mathrm{mmol} / \mathrm{l}$ ) in the stimulus end zone. Lake water was the control stimulus. The results are summarized in Table 1.

Excretions of conspecific donors evoked highly significant avoidance reactions with similar intensity in B. bufo and R. temporaria tadpoles. Effects were well reproducible: repeated experiment on $R$. temporaria gave a result not different from the first experiment $(\mathrm{p}=0.280)$. The avoidance reaction of $R$. arvalis was also significant, although slightly weaker. Ammonia solution with concentration of $0.2 \mathrm{mg} / 1$ was avoided by $B$. bufo and $R$. arvalis, but not by $R$. temporaria. The tadpoles of all three species avoided ammonia at $1.0 \mathrm{mg} / \mathrm{l}$ concentration. Thus, the threshold of reaction in larvae of two species was lower than $0.2 \mathrm{mg} / \mathrm{l}$. Ammonia solution of $1.0 \mathrm{mg} / \mathrm{l}$ 
was more effective than $0.2 \mathrm{mg} / \mathrm{l}$ for $B$. bufo and $R$. temporaria $(\mathrm{p}<0.01$ in both comparisons $)$. So, the reaction intensity depended on the concentration of this substance. The avoidance index increased insignificantly from $16.7 \pm 3.2$ to $20.4 \pm 3.36$ after additional stimulation of the $B$. bufo tadpoles motor activity in the end of excretion accumulation.

Stimulation with conspecific excretions or ammonia $1 \mathrm{mg} / \mathrm{l}$ often evoked changes of behavioral pattern of tadpoles: if the tadpole was on the presentation side when the stimulus was introduced, it moved to the opposite end of test aquarium; and if tadpole approached the stimulus zone later, it stopped abruptly, turned (sometimes after a few seconds) and quickly left this zone. As a rule, such reaction was observed repeatedly within a ten minute recording period. Some tadpoles did not swim more in the stimulus area after the first avoidance.

Differential sensitivity of $B$. bufo and R. temporaria tadpoles to ammonia solution

We studied the dependence of tadpole's avoidance reaction intensity on relations between levels of ammonia in the background and the stimulus solution. It was determined 14 average values for $B$. bufo tadpoles (Table 2). It was found that the threshold of behavioral response depended on ammonia background concentration. When it was very low $(<0.04 \mathrm{mg} / \mathrm{l}), B$. bufo larvae avoided the zone with elevated ammonia levels +0.2 , +0.5 and $+1.0 \mathrm{mg} / \mathrm{l}$. Thus, the absolute threshold of avoidance reaction to ammonia was smaller than $+0.2 \mathrm{mg} / \mathrm{l} \quad\left(+2 \cdot 10^{-7}\right)$. At the background concentration of $0.2 \mathrm{mg} / \mathrm{l}$, the threshold lied between +0.3 and $+1.0 \mathrm{mg} / \mathrm{l}$; at the background of $0.4 \mathrm{mg} / 1$ it lied between +1.5 and $+2.0 \mathrm{mg} / 1$ (but the stimulus of $2.5 \mathrm{mg} / 1$ did not evoke the reaction); at the background of $0.6 \mathrm{mg} / 1$ animals did not react to stimuli +2.0 and $+2.5 \mathrm{mg} / 1$, and at the background of $1.0 \mathrm{mg} / \mathrm{l}$ there were no reactions to stimuli +1.0 and $+3.0 \mathrm{mg} / \mathrm{l}$. Solutions with higher concentrations of ammonia were not presented due to possible toxic effects on the tadpoles.

It was impossible to evaluate the differential threshold $\mathrm{dI} / \mathrm{I}$ for the background $<0.04 \mathrm{mg} / \mathrm{l}$, because the exact value of the background level was unknown. Two significant results were obtained for higher values of the background: differential threshold of sensitivity for the background of $0.2 \mathrm{mg} / \mathrm{l}$ lied in the range $150 \%<\mathrm{dI} / \mathrm{I}$ $<500 \%$, and for background of $0.4 \mathrm{mg} / \mathrm{l}$ this value lied in the range $400 \%<\mathrm{dI} / \mathrm{I}<500 \%$.
Table 2. The dependence of the avoidance index for reaction of Bufo bufo tadpoles, entering the zone with elevated concentration of ammonia, on absolute and relative value of the stimulus at different ammonia backgrounds.

\begin{tabular}{|c|c|c|c|c|}
\hline $\begin{array}{c}\text { Backgrounc } \\
\mathrm{NH}_{3} \\
\mathrm{mg} / \mathrm{l}\end{array}$ & $\begin{array}{c}\text { Stimulus } \\
+\mathrm{NH}_{3} \\
\mathbf{m g} / \mathbf{l}\end{array}$ & $\begin{array}{c}\text { Stimulus/ } \\
\text { background } \\
\%\end{array}$ & $\begin{array}{l}\text { Avoidance } \\
\text { index } \\
\%\end{array}$ & $\begin{array}{c}\text { Significance } \\
\text { of the } \\
\text { reaction } \\
\text { compared } \\
\text { to control } \\
\mathbf{p}<\end{array}$ \\
\hline$<0.04$ & 0.2 & $>500$ & $21 \pm 5.3$ & 0.001 \\
\hline$<0.04$ & 0.5 & $>1250$ & $19 \pm 4.6$ & 0.000 \\
\hline$<0.04$ & 1.0 & $>2500$ & $13 \pm 3.4$ & 0.001 \\
\hline 0.2 & 0.3 & 150 & $2 \pm 3.4$ & 0.478 \\
\hline 0.2 & 1.0 & 500 & $22 \pm 4.3$ & 0.000 \\
\hline 0.4 & 1 & 250 & $0 \pm 4.0$ & 0.891 \\
\hline 0.4 & 1.5 & 380 & $7 \pm 4.5$ & 0.169 \\
\hline 0.4 & 2 & 500 & $17 \pm 4.4$ & 0.001 \\
\hline 0.4 & 2.5 & 630 & $4 \pm 3.6$ & 0.137 \\
\hline 0.6 & 1.5 & 250 & $-1 \pm 2.4$ & 0.696 \\
\hline 0.6 & 2.0 & 330 & $6 \pm 3.6$ & 0.387 \\
\hline 0.6 & 2.5 & 420 & $7 \pm 3.6$ & 0.897 \\
\hline 1.0 & 1.0 & 100 & $5 \pm 3.2$ & 0.258 \\
\hline 1.0 & 3.0 & 300 & $2 \pm 2.5$ & 0.697 \\
\hline
\end{tabular}

For tadpoles of $R$. temporaria 14 values were also obtained (Table 3). As might be expected, the avoidance threshold of zones with elevated ammonia concentration in these larvae depended on the background concentrations of test substance in media also. At the ammonia level of $0.15 \mathrm{mg} / \mathrm{l}$, the threshold lied about $+0.3 \mathrm{mg} / 1$, at the background level of $0.6 \mathrm{mg} / \mathrm{l}$ the threshold was less than $+1.2 \mathrm{mg} / \mathrm{l}$, and at background level of $1.1 \mathrm{mg} / \mathrm{l}$ it lied at $+1.1 \mathrm{mg} / \mathrm{l}$. Differential thresholds dI/I for the ammonia background of $0.15 \mathrm{mg} / \mathrm{l}$ were close to $200 \%(p<0.07)$; for the background of $0.6 \mathrm{mg} / 1$ they were much smaller; for the background of $0.8 \mathrm{mg} / 1$ the threshold lied close to $55 \%(\mathrm{p}<0.086)$, and for the background level of $1.1 \mathrm{mg} / 1$ threshold was equal to $100 \%$. Thus, the threshold for differential sensitivity of this tadpole species to the addition of ammonia decreases and become close to $100 \%$ when the ammonia background concentration increased.

The presentation of ammonia stimuli with two relative concentrations on several background levels of this substance allowed us to estimate the average values of the avoidance index for the groups under the same 
Table 3. The dependence of the avoidance index for reaction of Rana temporaria tadpoles, entering zone with elevated concentration of ammonia, from absolute and relative value of the stimulus at different ammonia backgrounds.

\begin{tabular}{cccccc}
\hline No. & Background $\mathbf{N H}_{\mathbf{3}}$ & Stimulus $+\mathbf{N H}_{\mathbf{3}}$ & $\begin{array}{c}\text { Stimulus/back-round } \\
\text { Avoidance index }\end{array}$ & $\begin{array}{c}\text { Significance of the } \\
\text { reaction compared } \\
\text { to control } \\
\mathbf{p} \leq\end{array}$ \\
\hline & $\mathbf{m g} / \mathbf{l}$ & $\mathbf{m g} / \mathbf{l}$ & $\mathbf{\%}$ & $\mathbf{\%}$ & 0.001 \\
& & & & 0.001 \\
2 & 0.15 & 1.5 & +1000 & $28.5 \pm 4.8$ & 0.071 \\
3 & 0.15 & 0.75 & +500 & $25.1 \pm 3.9$ & 0.184 \\
4 & 0.15 & 0.3 & +200 & $14.8 \pm 8.1$ & 0.090 \\
5 & 0.15 & 0.15 & +100 & $7.1 \pm 5.2$ & 0.831 \\
6 & 0.4 & 0.4 & +100 & $10.0 \pm 6.6$ & 0.001 \\
7 & 0.6 & 0.6 & +100 & $1.7 \pm 5.9$ & 0.084 \\
8 & 0.6 & 1.2 & +200 & $20.5 \pm 5.1$ & 0.053 \\
9 & 0.8 & 0.4 & +50 & $13.8 \pm 7.0$ & 0.086 \\
10 & 1.1 & 1.1 & +100 & $19.7 \pm 5.9$ & 0.160 \\
11 & 1.1 & 0.6 & +55 & $9.4 \pm 6.3$ & 0.003 \\
12 & 1.1 & 0.2 & +18 & $5.7 \pm 3.8$ & 0.001 \\
13 & 1.1 & 2.2 & +200 & $16.9 \pm 4.8$ & 0.009 \\
\hline 14 & & & +200 all & $17.5 \pm 3.4$ & \\
\hline
\end{tabular}

In the first column: $1-12$ - numbers of experiments; 13 - the processing of pooled data obtained in experiments number $3,7,12$ $(+200 \%) ; 14$ - the processing of pooled data obtained in experiments number 4, 5, 6, 9 (+100\%).

relative exceed of background (Table 3, lines 13 and 14). The average relative stimulus $200 \%$ induced highly significant and rather intense reaction. Reaction to the relative stimulus $100 \%$ was also highly significant due to a large number of experimental animals, but its intensity was low.

\section{Discussion}

The results of our experiments show that tadpoles of three anuran species at stages 36-39 perceived tested chemical stimuli and reacted changing their behavior. Clearly identified avoidance of conspecific tadpoles excretions, as well as ammonia solutions at a concentration of $1.0 \mathrm{mg} / \mathrm{l}$, was manifested as a change in the observed motor activity and as reducing the time spent by tadpoles at the stimulus side comparing with the control.

Previously, it was reported that a short-term enhancement of motor activity of $R$. aurora tadpoles in aggregations was accompanied with an increase of ammonia concentration in water by $35 \%$. Perception of such water by other tadpoles of the same species evoked an increase of the time spent in shelters and a decrease of the time spent moving (Kiesecker et al. 1999). The authors showed that adding about $1.0 \mathrm{mg} / \mathrm{l}$ ammonia caused similar changes in the behavior of recipients. Comparable results were obtained in tadpoles of $B$. bufo (Manteifel et al. 2006). Our data together with results of experiments of Kiesecker et al. (1999) showed that tadpoles of all four studied anuran species avoid areas of elevated ammonia concentration.

A full analysis of the tadpole excretions is impossible, but ammonia is at least one of the stimulus components that cause an avoidance reaction. In our experiments, the minimal effective increase of ammonia concentration for two tadpole species of three was $+12 \mathrm{mmol} / \mathrm{l}$, that is about five times less than in the experiments made by Kiesecker et al. (1999). These authors introduced the term «disturbance pheromone» to distinguish it from the term «alarm pheromone», which is attributed to active ingredients of excretions from the damaged skin of many fish and some anuran larvae (Pfeiffer 1974). Avoidance of a disturbance pheromone may increase the probability of amphibian larvae survival.

In aggregations of several species of anuran larvae, which are common in small ponds and are often 
characterized by a high density of individuals, there are conditions not only for intraspecific chemical communication using excretions, but also for interspecific interaction using non-specific pheromone signaling on the presence of disturbing objects (primarily, potential predators). But can the increase of the ammonia concentration in water really act as a disturbance pheromone? Situations with nonspecific disturbance signal are quite common in the nature for acoustic and optical alarm signals that cause alertness or avoidance of many stimuli in animals of different species (Lima and Dill 1970). Aquatic animals of various taxonomic groups may use the non-specific ammonia signal caused by the action of threatening stimuli on other members of the local community. Such communication can reduce the probability of meeting with predators for recipients.

Parameters of the tadpole differential chemosensory sensitivity to ammonia correspond to the assumption that this substance could play signaling role. There is a principal dependence of the threshold of avoidance reaction to a zone with elevated ammonia concentration in water on the background ammonia level. The magnitude of the differential thresholds $\mathrm{dI} / \mathrm{I}$ lies in the range $400-500 \%$ for B. bufo tadpoles, and 100-200\% for $R$. temporaria ones. These values are much higher than known for fish and human olfactory and gustatory sensitivities (Moncrieff 1967, Neuhaus and Appelbaum 1980, Doty 1991), which were estimated in the range of 3-36\%. Unfortunately, these values are not a reliable material for comparisons. So, the human olfactory threshold quite variably depends on evaluation methods (Cain 1977, Doty et al. 1986). According to recent data, the threshold of olfactory perception of ammonia vapors in humans is $2.6 \cdot 10^{-6} \mathrm{~g} / \mathrm{ml}$, whereas the threshold of irritating action of these vapors is $12-25$ times higher (Smeets et al. 2007). The solubility of this substance in water is very high (seven hundreds volumes of gas per one volume of water), and ammonia can be accumulated in the mucus of olfactory organs in air-breathing vertebrates.

\section{References}

CAIN WS: Differential sensitivity for smell: "Noise" at the nose. Science 195: 796-798, 1977.

COON SL, WALCH M, FITT WK, WEINER RM, BONAR DB: Ammonia induces settlement behavior in oyster larva. Biol Bull 179: 297-303, 1990.

DOTY RL: Psychophysical measurement of odor perception in humans. In: The Human Sense of Smell. RL DOTY, W
The methodical identity allows us to compare the possible functional significance of differential sensitivity to ammonia for $B$. bufo and R. temporaria tadpoles. The thresholds of $R$. temporaria (100-200\%) are 3-4 times less than in B. bufo (400-500 \%). Thus, our data show that probability of ammonia perception and it usage as a disturbance pheromone or as one of its components by $B$. bufo tadpoles is restricted by waters with the background ammonia level not more than $0.4 \mathrm{mg} / \mathrm{l}$. Perception of ammonia by $R$. temporaria tadpoles is not restricted in the all range of its background concentrations from 0.05 to $1.1 \mathrm{mg} / \mathrm{l}$ and more. Such limits of the "operating range" correspond to the natural conditions: the concentration of ammonia in the shore waters of the lake Glubokoe lay in the range 0.06-0.1 mg/l mainly. The observed species differences of differential sensitivity may be explicable by ecological specifics: in contrast to $R$. temporaria, the $B$. bufo larvae have several antipredator mechanisms and should be less dependent on the response to non-specific pheromone.

Communicative role of simple substances is a perspective area for further study of their role in the chemical communication of animals. It is known, that the increasing in ammonia concentration evokes the settlement of larvae in marine mollusk mussel (Coon et al. 1990). Ammonia is also a human sweat secretion transmitting yellow fever (Geier et al. 1999). There is no doubt that further investigations on the signaling role of low-molecular weight pheromones will reveal new aspects of non-specific metabolites action in the organization of animal populations.

\section{Conflict of Interest}

There is no conflict of interest.

\section{Acknowledgements}

This work was supported by the Russian Foundation for Basic Research (Project 10-04-00019). component, which attract mosquitoes Aedes aegypti,

\footnotetext{
BREIPOHL (eds), Springer Verlag, Berlin, 1991, pp 95-134.
} 
DOTY RL, GREGOR TP, SETTLE RG: Influence of intertrial interval and sniff-bottle volume on phenyl ethyl alcohol odor detection thresholds. Chem Senses 11: 259-264, 1986.

DUELLMAN WE, TREUB L: Biology of Amphibians. McGraw-Hill, New York, 1986.

GEIER M, BOSCH OJ, BOECKH J: Ammonia as an attractive component of host odour for the yellow fever mosquito, Aedes aegypti. Chem Senses 24: 647-653, 1999.

GOSNER K: A simplified table for staging anuran embryos and larvae with notes on identification. Herpetologica 16: 183-190, 1960.

KIESECKER JM, CHIVERS DP, MARCO A, QUILCHANO C, ANDERSON MT, BLAUSTEIN AR: Identification of a disturbance signal in larval red-legged frogs, Rana aurora. Anim Behav 57: 1295-1300, 1999.

LIMA SL, DILL LM: Behavioral decisions made under the risk of predation: a review and prospectus. Can J Zool 68 : 619-640, 1990.

MANTEIFEL Y: Chemically-mediated avoidance of predators by Rana temporaria tadpoles. $J$ Herpetol 29: 461-463, 1995.

MANTEIFEL YB, MARGOLIS SE, KISELEVA EI: Disturbance pheromone in the common toad (Bufo bufo) larvae: the possible communicative role of ammonium-containing excretions. Dokl Biol Sci 406: 82-83, 2006.

MONCRIEFF RW: The Chemical Senses. Leonard Hill, London, 1967, 760 p.

NEUHAUS W, APPELBAUM S: Quantitative Bestimmung der Geruchsadaptation bei Phoxinus laevis L. und die Bedeutung der Adaptation bei der Geruchsorientierung der Wanderfische. Zool Jahrb Physiol 84: 458-471, 1980.

PFEIFFER W: Pheromones in fish and amphibian. In: Pheromones. North Holland Publ. Co. Amsterdam, London, 1974, pp 269-296.

SMEETS MAM, BULSING PJ, VAN ROODEN S, STEINMANN R, DE RU JA, OGINK NWM, VAN THRIEL C, DALTON PH: Odor and irritation thresholds for ammonia: a comparison between static and dynamic olfactometry. Chem Senses 32: 11-20, 2007.

STONE H, BOSLEY J: Olfactory discrimination and Weber's law. Percept Mot Skills 20: 657-665, 1965.

WASSERSUG RJ, VON SECKENDORF HK: The kinematics of swimming in anuran larvae. $J$ Exp Biol 119: 1-30, 1985. 